\title{
The Comparison and Analysis of Wastewater Drainage and Treatment between China and Western Countries
}

\author{
T.A. JIANG ${ }^{1}$ \\ ${ }^{1}$ Bard College at Simon's Rock, MA, United States
}

\begin{abstract}
KEYWORD: Wastewater; Drainage; Treatment; Sewage
ABSTRACT: Water is crucial in the development of any country. Furthermore, water is used in the everyday life, and thus a huge amount of wastewater is created. It is important to treat the wastewater properly, because it can affect the environment to an unimaginable extent. Via comparing situations in China and those in Western countries (European countries and the United States), this article deals with wastewater treatment from the following three aspects: domestic wastewater drainage and treatment, storm water drainage and treatment, and farming wastewater drainage and treatment.
\end{abstract}

\section{INTRODUCTION}

Nowadays, natural resources are a crucial element with regard to a nation's development. Among all sorts of natural resources, water is definitely one of the closest to the daily life. Every day, water is an essential for human-beings and other creatures. Since huge amount of water is consumed each day, huge amount of wastewater is also created each day. Therefore, how to deal with wastewater becomes a critical issue. Although water is renewable natural resources, it is still worth getting attention from scholars and government officials to every single citizen. In order to keep this precious resources refreshing and renewing itself healthily, everybody as part of the interaction with natural resources ought to carry out certain responsibilities to ensure that our waste water is properly treated before drainage. Furthermore, it is visionary to put sufficient efforts into the protection of water resources.

\section{DOMESTIC WASTEWATER DRAINAGE AND TREATMENT}

\section{Combined sewer-systems}

As the name suggests, the combined sewer-system (CSS) is a network of sewage that serves a city as a whole. "As a whole" refers to the confluence of domestic wastewater and storm water (which will be further discussed in the next section). The conversion of these two kinds of water has an obvious weakness: the water load. In general, the sewage system has enough space for carrying domestic wastewater. However, this is not true anymore when storms occur (see next section for details). Thus in consideration of domestic wastewater conveyance only, the CSS may be a suitable form, but the complex urban situations and the high standard for crowded urban traffic road make the CSS imperfect. Nonetheless, the cost of it is relatively considerable because the system is built as a whole and no other parts or sub-systems need to be constructed separately.

Some European cities were the first to use this form of sewage system, followed by the United States in the later half of the nineteenth century. The first CSS in the United States was built in the 1850s in Chicago and Brooklyn - both metropolitans. Since then, the United States has then been using the CSS until the beginning of the twentieth century. (Burian et al. 2000)

Cities in China mostly use this form of sewer system as a default setting. In China, domestic waste water, industrial wastewater and storm water all go into the same sewer. Thus it is not hard to imagine that the sewer system in Chinese cities carry great burdens. Especially for cities in the south of China, huge amount of rainfall is very likely to affect the drainage and treatment of the regular domestic wastewater.

\section{Separate sewer-systems}

In contrast to CSS, the separate sewer-system (SSS) has more than one complete system. The one system deals with domestic wastewater coming from homes int he city and the other one deals with 
storm water carrying it into a waterbody. This sewage system costs a lot more than the CSS, but it treats different types of water smartly. This discriminative treatment against two types of water will have numerous advantages which will be discussed in the next section on storm water drainage and treatment.

\section{Combination of CSSs and SSSs}

Many were led into a new way while trying to decide between the CSS and the SSS. That is - trying to combine both. The advantages of the CSS may work well with the advantages of the SSS. However, it may cause chaos if the layout of the underground sewage system in a city is not consistent and involves various forms. (Jin \& Yu 2002) So now, the question left to consider is where to use the CSSs and where to use the SSSs. This question was addressed by Rudolph Hering. He suggested that whether to use a CSS or a SSS depends on the city's financial situation. (Burian et al. 2000)

\section{Centralized and decentralized sewer-systems}

All of the cases above are pertaining to centralized sewer-systems which are a modern thing compared to the pre-world-war time. However, it doesn't mean that the decentralized sewer-system in which each family has an access to a privy cesspool. The decentralized system is more suitable for the extremely low-density rural area. In those areas, it is way more costly to build a complete sewer network than to build private mini-sewers that serve each family very well. (Burian et al. 2000)

\section{Comparison and analysis}

By comparing the United States and China, it is evident to tell that both the US and China have underwent or is currently undergoing a process in which the European sewage development stands as an exemplar. European countries are the first ones to set up complete and organized sewage systems, so the sewage development history of the United States involves traces of experiences borrowed from countries like Germany. (Weichgrebe, unpbl.) However, the more recent the time is, the more independent the development is from that of European countries. For China, this observation can be meaningful. It may not be helpful if Chinese cities and rural areas just copy the experiences from the western countries, which may lead to malfunctions of the sewage municipalities.

To well-establish a sewage system, related experts and engineers ought to take into account various factors including regional climate and weather, underground situations, and local residents' structure which may differentiate the amount and components of the domestic wastewater. For example, if the percentage of senior citizens in a local area is higher than those in other areas, then the wastewater amount may be lower because senior citizens are generally more frugal. If a local area has more than average number of hospitals and clinics, then the amount of wastewater in that area is very likely to be relatively high, because the special condition of hospitals and clinics requires a higher standard of cleaning and thus significantly more wastewater is generated every day.

\section{STORM WATER DRAINAGE AND TREATMENT}

\section{Potential predicaments caused by storm water}

Overflows can happen. Especially when heavy rains or snows occur, it is very likely that most of the precipitation water may add burdens to the sewage systems. Huge amount of atmospheric water may be absorbed by natural landscapes such as wetlands and by cracks on the road. After that, instead of going into streams, the flows will be mixed up in sewages with domestic wastewater. This increases the possibility of sewage overflow tremendously. Once overflows occur, the untreated water will pollute surrounding environment. For example, nearby farming lands or private gardens may be polluted affecting residents' health; open swimming areas such as lakes and rivers may bring pools of germs, viruses and hazardous chemicals to uninformed swimmers. (Cheng 2009)(Wang 2008)

\section{Sewage size as a solution}

Seeking the reasons why precipitation water is a big problem concerning flood in China, the size of sewages is a main focus. There is a misleading misconception in China that the wider the sewage is, the better it is for the drainage of rain or snow water. It was reported how wide sewages in other 
countries are, wide enough for a running car. Sewages in foreign countries, especially European countries, have become a main target for comparisons with domestic ones in China.

Hamburg, Germany, is usually the case discussed and compared with China pertaining to Sewage size. Pipes in Germany are wide enough for a running car, which is significantly wider than that of China. In China, many have been advocating for an expansion in sewage size. The adequate space underground ensures the carrying capacity under extreme weather condition.

However, in most areas, at least mostly in China, significant amount of precipitation does not occur all year round. Even in the South where precipitation is predictably adequate, the seasonal distribution of rainfall is still relatively stable. Generally more rainfall occur in springs and summers than do in falls and winters. Hence, if the sewage size is uniformly expanded, the extra space may be wasted in dry seasons, because only domestic wastewater runs through the sewage system. Furthermore, if the expansion is indeed necessary, the extent to which the facilities are expanded is a though choice. It certainly does not worth it adjusting the whole system but not fulfilling the purpose of preventing sewage overflows in wet seasons. However, it is hard to predict how much wider the system should be expanded since it is had to predict the climate or weather trend in a very long term.

\section{Water conservation as a solution}

Sewage size is not the only potential solution considering storm water drainage. Storm water is categorized as precipitation water, and thus is part of the water circulation. Since controlling weather with human intervention is not economically realistic in a short term and not environmentally appropriate in a long term, the answer is left to improving local water circulatory conditions. This improvement can be achieved via building dams, reservoirs, and other water conservatories. Conservatories serve as simulations to natural water storage. These conservatories will stabilize the precipitation, at a local geographic range, achieving a "natural hydro-balance".

Hamburg, Germany, the same example as above, applies that principle.

However, the "natural hydro-balance" is already to some extent realized in southern China. For example, in Shenzhen, there are about 18 reservoirs in 2086.6 square kilometers (about 815 square miles). In addition to other water bodies like lakes and rivers, the capability of water adjustment is optimistic.

\section{Comparison and analysis}

It is debate in China now whether to expand at the sewage system or not. From a short term aspect, it may give improvement to storm water drainage immediately, but not effectively enough. Besides, economic issues can be a great obstacle to that solution. "natural hydro-balance", which involves building a lot of water conservatories, is a long-term beneficial solution. It may not bring positive effects immediately, but will better storm water drainage in a much more sustainable way.

\section{FARMING WASTEWATER DRAINAGE AND TREATMENT}

\section{Livestock wastewater and its potential effect}

Livestock raising needs huge amount of water everyday. Most of the water contributes to hygiene processes. For example, the animals need showers to keep clean and healthy. The pigsties need cleaning regularly and frequently because the excretion of the animals may carry diseases, and affect not only the health of residents nearby but also the food safety of meat consumers. Furthermore, the wastewater of livestocks may leak into the ground and contaminate the soil, expanding the food safety problem to veggies and crops.

Farms and livestock raising spots are usually located outside the urban areas. When looking at the wastewater treatment condition in small towns in China, the percentage of wastewater treatment coverage is not even $10 \%$. As for rural eras, the percentage can only be lower. Therefore, it is a severe problem that the hygiene of livestock raising field in China be bettered.

\section{Possible solutions and ideas}

As for western countries, the situation is much more different. Using the author's experience in the Michigan in the United States as an example, the farming areas are usually perceived as a natural paradise to live in and to get organic food from. Michigan is a big agricultural state with tons of 
small private farms. Local residents or residents of nearby towns often come and purchase meat product and vegetables from the local farmers. It is not difficult to tell from those local residents that the food from large retail merchants is not safe or clean enough for them to put their hearts in their stomachs. Local farms in the United States have a form of setting up the farm as an ecofriendly system. The cattle help the crops and the crops help the cattle as well. The wastewater is treated properly and no potential contamination may get into the lives of others.

There are similar paradigms in China however, that a farm is eco-friendly and the products are safe from the potential contamination from the cattle and livestocks. One of the paradigms within the author's knowledge is the Guangming Farm in Shenzhen, Guangdong. This farm uses various sources of water and allocates sufficient attention to the proper treatment of the farm's wastewater. It is easy to understand why the owners attribute so much focus to wastewater treatment. The farm is huge in size. Water containing the waste from the cattle may affect their whole product chain including tourism. The farm raises various livestocks including domesticated fowls and cultivates numerous types of fruits. The improper treatment of wastewater containing germs and other hazardous chemicals from the cattle may have a tremendously negative effect on other livestocks and plants. Furthermore, the idea of the tertiary industry not only increases the income of the farm, but also ensures a certain amount of inspection on the hygiene condition of the farm because it is ideal to show the tourists the best of the farms.

\section{Comparison and Analysis}

Agricultural and livestock industry can be a crucial part in a country's economic pyramid. Different aspects considering farming water includes proper wastewater treatment before reusing or disposal, forming a natural ecosystem within a farm, and developing the tertiary industry properly if possible.

\section{CONCLUSION}

Water drainage is a complex topic pertaining but not limited to the aspects discussed in this article: domestic wastewater, storm water, and farming waste water drainage and treatment. To achieve an ideal status in which contamination from sewage system is minimized as close to zero as possible, efforts are expected to be seen from different aspects. Governments shall make wise choices concerning the sewage systems, and may give financial support when necessary. Farmers shall focus on the eco-stability within the farms as well as the pre-disposal or pre-reuse treatment of wastewater. Solving problems and improving situations pertaining to wastewater drainage and treatment are not limited to one or several ideas. Just as the tertiary industry can help farms with environmental issues concerning wastewater, other wastewater problems may be solved as well from brand-new and creative ideas.

\section{REFERENCES}

[1] Burian, S.J., Nix, S.J., Pitt, R.E., Durrans, S.R. 2000. Wastewater Management in the United States: Past, Present, and Future. Journal of Urban Technology (ISSN:1063-0732 paper/ISSN: 1466-1853 online) volume 7, number 3: page 43,53-57.

[2] Cheng, G.W. 2009. Water Pollution Control Engineering. Beijing: Chemical Industry Press.

[3] Jin, Z.F., Yu, Z.R. 2002. Sewage Treatment Combined Craft and Engineering Application. Beijing: Chemical Industry Press.

[4] Wang, Y.F. 2008. Water Pollution Control Technology. Beijing: Chemical Industry Press.

[5] Weichgrebe, D. unpbl. Sewage Treatment Development History and Current Situations of German Cities. 